\title{
Investigation of Clostridium difficile interspecies relatedness using multilocus sequence typing, multilocus variable-number tandem-repeat analysis and antimicrobial susceptibility testing
}

\author{
C. Rodriguez a,*, V. Avesani ${ }^{\text {b }}$, B. Taminiau ${ }^{\text {a }}$, J. Van Broeck ${ }^{\text {b }}$, B. Brévers ${ }^{\text {a }}$, M. Delmée ${ }^{\text {b }}$, \\ G. Daube ${ }^{a}$ \\ a Food Science Department, FARAH, Faculty of Veterinary Medicine, University of Liège, Boulevard de Colonster 20, 4100 Liège, Belgium \\ ${ }^{\mathrm{b}}$ Microbiology Unit, Catholic University of Louvain, Avenue Hippocrate B1.54.01, 1200 Brussels, Belgium
}

\section{A R T I C L E I N F O}

\section{Article history:}

Accepted 3 September 2015

\section{Keywords:}

Animals

Clostridium difficile

Humans

Multilocus sequence typing

Multilocus variable-number tandem-repeat analysis

\begin{abstract}
A B S T R A C T
Multilocus sequence typing (MLST), multilocus variable-number tandem-repeat analysis (MLVA) and antimicrobial susceptibility were performed on 37 animal and human C. difficile isolates belonging to 15 different PCR-ribotypes in order to investigate the relatedness of human and animal isolates and to identify possible transmission routes.

MLVA identified a total of 21 different types while MLST only distinguished 12 types. Identical C. difficile strains were detected in the same animal species for PCR-ribotypes 014, 078, UCL 16U and UCL 36, irrespective of their origin or the isolation date. Non clonal strains were found among different hosts; however, a high genetic association between pig and cattle isolates belonging to PCR-ribotype 078 was revealed. MLVA also showed genetic differences that clearly distinguished human from animal strains. For a given PCR-ribotype, human and animal strains presented a similar susceptibility to the antimicrobials tested. All strains were susceptible to vancomycin, metronidazole, chloramphenicol and rifampicin, while PCRribotypes 078, UCL 5a, UCL 36 and UCL 103 were associated with erythromycin resistance.

The data suggest a wide dissemination of clones at hospitals and breeding-farms or a contamination at the slaughterhouse, but less probability of interspecies transmission. However, further highly discriminatory genotyping methods are necessary to elucidate interspecies and zoonotic transmission of $C$. difficile.
\end{abstract}

(c) 2015 Elsevier Ltd. All rights reserved.

\section{Introduction}

Clostridium difficile is an anaerobic spore-forming bacterium responsible for serious enterocolitis in humans and animals. Several outbreaks have been reported in recent years, particularly in hospitals, making $C$. difficile a primarily nosocomial pathogen in humans (Jones et al., 2013). However, the increasing number of $C$. difficile infections (CDI) acquired in the community (Hensgens et al., 2012) and the large number of reports describing food (Rodriguez-Palacios et al., 2013), animal (Susick et al., 2012) and environmental (Zidaric et al., 2010; Hargreaves et al., 2013) reservoirs of the bacterium suggest possible transmission outside healthcare settings. For this reason, several studies have considered food and animals as potential sources for human community-acquired CDI (Rodriguez-Palacios et al., 2013).

\footnotetext{
* Corresponding author. Tel.: +32 43664015 .

E-mail address: c.rodriguez@ulg.ac.be (C. Rodriguez).
}

Previous studies have focused on comparing $C$. difficile isolates from diverse sources and hosts (Lemée et al., 2005; Bakker et al., 2010; Griffiths et al., 2010; Stabler et al., 2012). Multilocus variablenumber tandem-repeat analysis (MLVA) and multilocus sequence typing (MLST) have been recently developed to bring out phylogenetic relationships among the $C$. difficile population. MLVA shows a high level of discrimination and is considered useful for tracking outbreak strains geographically and for identifying cross-infection clusters between patients (Killgore et al., 2008; Manzoor et al., 2011). Data obtained by MLST can be used to determine the molecular phylogeny of $C$. difficile isolates and are highly transportable interlaboratory (Killgore et al., 2008).

Few studies using MLVA and MLST methods have focused on comparing human and animal isolates. Three previous studies (Lemée et al., 2004, 2005; Stabler et al., 2012) analysed isolates from various hosts by MLST, and the MLVA technique has been applied to determine the relatedness of C. difficile PCR ribotype 078 and 027 isolates from different hosts (Debast et al., 2009; Bakker et al., 2010).

In this study MLVA and MLST were both used to investigate genetic relationships between $C$. difficile isolates from human faecal 
Table 1

PCR-ribotypes, toxin activity, gen profile and in vitro antibiotic resistance of the human and animal strains characterised by MLST.

\begin{tabular}{|c|c|c|c|c|c|c|c|c|c|c|}
\hline \multirow{2}{*}{$\begin{array}{l}\text { Strain } \\
\text { identification }\end{array}$} & \multirow[t]{2}{*}{ Origin } & \multirow[t]{2}{*}{ Source } & \multirow[t]{2}{*}{ PCR-ribotype } & \multirow{2}{*}{$\begin{array}{c}\text { Toxin } \\
\text { activity }^{\mathrm{a}}\end{array}$} & \multirow[t]{2}{*}{ Toxin genes $^{\mathrm{b}}$} & \multicolumn{3}{|c|}{$t_{c d C}$ deletion ${ }^{\mathrm{b}}$} & \multicolumn{2}{|c|}{ GyrA mutation $^{\mathrm{b}}$} \\
\hline & & & & & & tcdC $18 b p$ & $t c d C 36 b p$ & tcdC 117 & gyrA Mut $1 A$ & gyrA Mut $1 B$ \\
\hline 5828 & Human & $\mathrm{NRCCD}^{\mathrm{d}}$ & 078 & + & $\mathrm{A}^{+} \mathrm{B}^{+} \mathrm{CDT}^{+}$ & - & + & - & - & - \\
\hline 5063 & Human & $\mathrm{NRCCD}^{\mathrm{d}}$ & 078 & + & $\mathrm{A}^{+} \mathrm{B}^{+} \mathrm{CDT}^{+}$ & - & + & - & + & - \\
\hline 4667 & Human & $\mathrm{NRCCD}^{\mathrm{d}}$ & 078 & + & $\mathrm{A}^{+} \mathrm{B}^{+} \mathrm{CDT}^{+}$ & - & + & - & - & - \\
\hline 6136 & Pig & Intestinal contents $\mathrm{e}^{\mathrm{e}}$ & 078 & + & $\mathrm{A}^{+} \mathrm{B}^{+} \mathrm{CDT}^{+}$ & + & - & + & - & - \\
\hline 6135 & Pig & Intestinal contents ${ }^{\mathrm{e}}$ & 078 & + & $\mathrm{A}^{+} \mathrm{B}^{+} \mathrm{CDT}^{+}$ & + & - & + & - & - \\
\hline 7485 & Cow & Intestinal contents ${ }^{\mathrm{f}}$ & 078 & + & $\mathrm{A}^{+} \mathrm{B}^{+} \mathrm{CDT}^{+}$ & - & + & - & - & - \\
\hline 6423 & Cow & Intestinal contents $\mathrm{f}^{\mathrm{f}}$ & 078 & + & $\mathrm{A}^{+} \mathrm{B}^{+} \mathrm{CDT}^{+}$ & - & + & - & + & - \\
\hline 1101 & Human & $\mathrm{NRCCD}^{\mathrm{d}}$ & UCL 11 & + & $\mathrm{A}^{+} \mathrm{B}^{+} \mathrm{CDT}^{+}$ & NT & NT & NT & NT & NT \\
\hline 6412 & Cow & Carcass $^{f}$ & UCL 11 & + & $\mathrm{A}^{+} \mathrm{B}^{+} \mathrm{CDT}^{+}$ & - & + & - & - & - \\
\hline 5001 & Human & $\mathrm{NRCCD}^{\mathrm{d}}$ & UCL 5a & + & $\mathrm{A}^{+} \mathrm{B}^{+} \mathrm{CDT}^{+}$ & NT & NT & NT & NT & NT \\
\hline 6408 & Cow & Carcass $^{f}$ & UCL 5a & + & $\mathrm{A}^{+} \mathrm{B}^{+} \mathrm{CDT}^{+}$ & - & + & - & + & - \\
\hline 4592 & Human & $\mathrm{NRCCD}^{\mathrm{d}}$ & 014 & + & $\mathrm{A}^{+} \mathrm{B}^{+} \mathrm{CDT}^{-}$ & - & - & - & - & - \\
\hline 4455 & Human & $\mathrm{NRCCD}^{\mathrm{d}}$ & 014 & + & $\mathrm{A}^{+} \mathrm{B}^{+} \mathrm{CDT}^{-}$ & - & - & - & - & - \\
\hline 6420 & Cow & Intestinal contents ${ }^{\mathrm{f}}$ & 014 & + & $\mathrm{A}^{+} \mathrm{B}^{+} \mathrm{CDT}^{-}$ & - & - & - & - & - \\
\hline 7071 & Pig & Carcass $^{\mathrm{f}}$ & 014 & + & $\mathrm{A}^{+} \mathrm{B}^{+} \mathrm{CDT}^{-}$ & - & - & - & - & - \\
\hline 6414 & Pig & Carcass $^{\mathrm{f}}$ & 014 & + & $\mathrm{A}^{+} \mathrm{B}^{+} \mathrm{CDT}^{-}$ & - & - & - & - & - \\
\hline 6415 & Pig & Carcass $^{\mathrm{f}}$ & 014 & + & $\mathrm{A}^{+} \mathrm{B}^{+} \mathrm{CDT}^{-}$ & - & - & - & - & - \\
\hline 6427 & Cow & Intestinal contents $\mathrm{f}^{\mathrm{f}}$ & UCL 16L & + & $\mathrm{A}^{+} \mathrm{B}^{+} \mathrm{CDT}^{-}$ & - & - & - & - & - \\
\hline 1601 & Human & $\mathrm{NRCCD}^{\mathrm{d}}$ & UCL $16 U$ & + & $\mathrm{A}^{+} \mathrm{B}^{+} \mathrm{CDT}^{-}$ & NT & NT & NT & NT & NT \\
\hline 6410 & Cow & Carcass $^{f}$ & UCL $16 U$ & + & $\mathrm{A}^{+} \mathrm{B}^{+} \mathrm{CDT}^{-}$ & - & - & - & - & - \\
\hline 6413 & Cow & Carcass $^{f}$ & UCL $16 U$ & + & $\mathrm{A}^{+} \mathrm{B}^{+} \mathrm{CDT}^{-}$ & - & - & - & - & - \\
\hline 4597 & Human & $\mathrm{NRCCD}^{\mathrm{d}}$ & 015 & + & $\mathrm{A}^{+} \mathrm{B}^{+} \mathrm{CDT}^{-}$ & NT & NT & NT & NT & NT \\
\hline 6409 & Cow & Carcass $^{f}$ & 015 & + & $\mathrm{A}^{+} \mathrm{B}^{+} \mathrm{CDT}^{-}$ & + & - & - & - & - \\
\hline 8387 & Human & $\mathrm{NH}^{\mathrm{c}}$ & UCL 36 & - & $\mathrm{A}^{-} \mathrm{B}^{-} \mathrm{CDT}^{-}$ & - & - & - & - & - \\
\hline 8378 & Human & $\mathrm{NH}^{\mathrm{c}}$ & UCL 36 & - & $\mathrm{A}^{-} \mathrm{B}^{-} \mathrm{CDT}^{-}$ & - & - & - & - & - \\
\hline 7083 & Pig & Carcass $^{f}$ & UCL 36 & - & $\mathrm{A}^{-} \mathrm{B}^{-} \mathrm{CDT}^{-}$ & - & - & - & - & - \\
\hline 7078 & Pig & Carcass $^{f}$ & UCL 36 & - & $\mathrm{A}^{-} \mathrm{B}^{-} \mathrm{CDT}^{-}$ & - & - & - & - & - \\
\hline 8101 & Human & $\mathrm{NRCCD}^{\mathrm{d}}$ & 081 & + & $\mathrm{A}^{+} \mathrm{B}^{+} \mathrm{CDT}^{-}$ & NT & NT & NT & NT & NT \\
\hline 7077 & Pig & Carcass $^{\mathrm{f}}$ & 081 & + & $\mathrm{A}^{+} \mathrm{B}^{+} \mathrm{CDT}^{-}$ & - & - & - & - & - \\
\hline 6140 & Pig & Intestinal contents ${ }^{\mathrm{e}}$ & 081 & + & $\mathrm{A}^{+} \mathrm{B}^{+} \mathrm{CDT}^{-}$ & - & - & - & - & - \\
\hline 4181 & Human & $\mathrm{NRCCD}^{\mathrm{d}}$ & UCL 46 & + & $\mathrm{A}^{+} \mathrm{B}^{+} \mathrm{CDT}^{-}$ & - & - & - & - & - \\
\hline 7488 & Pig & Intestinal contents $\mathrm{f}^{\mathrm{f}}$ & UCL 46 & + & $\mathrm{A}^{+} \mathrm{B}^{+} \mathrm{CDT}^{-}$ & - & - & - & - & - \\
\hline 6421 & Cow & Intestinal contents ${ }^{\mathrm{f}}$ & UCL 118 & + & $\mathrm{A}^{+} \mathrm{B}^{+} \mathrm{CDT}^{-}$ & - & - & - & - & - \\
\hline 6425 & Cow & Intestinal contents ${ }^{\mathrm{f}}$ & UCL 270 & - & $\mathrm{A}^{-} \mathrm{B}^{-} \mathrm{CDT}^{-}$ & - & - & - & - & - \\
\hline 7487 & Cow & Intestinal contents ${ }^{\mathrm{f}}$ & UCL 103 & - & $\mathrm{A}^{-} \mathrm{B}^{-} \mathrm{CDT}^{-}$ & - & - & - & - & - \\
\hline 6430 & Cow & Intestinal contents ${ }^{\mathrm{f}}$ & UCL 254 & + & $\mathrm{A}^{+} \mathrm{B}^{+} \mathrm{CDT}^{-}$ & - & - & - & - & - \\
\hline 6411 & Cow & Carcass $^{\mathrm{f}}$ & 023 & + & $\mathrm{A}^{+} \mathrm{B}^{+} \mathrm{CDT}^{+}$ & + & + & - & - & - \\
\hline
\end{tabular}

NT, not tested.

a Toxin activity was determined using confluent monolayer MRC-5 cells.

b Results obtained by the Genotype CDiff test system and/or multiplex PCR.

c C. difficile isolates from patients of a Belgian nursing home (unpublished data).

d C. difficile strains isolated from hospitalised patients at the Belgium National Reference Centre for Clostridium difficile.

e Rodriguez et al. (2012).

f Rodriguez et al. (2013).

samples, pig and cattle intestinal and carcasses samples isolated in the same geographic region and during the same time period. Additionally, all of the isolates were characterised and compared with respect to their antibiotic resistance.

\section{Materials and methods}

Isolates

A total of 37 isolates were investigated. Eleven human isolates were obtained from the C. difficile collection at the Microbiology Unit, Catholic University of Louvain (the human C. difficile reference laboratory in Belgium). Another two human isolates were obtained from aged residents at a local Belgian nursing home. In animals, a total of 24 isolates were analysed; 12 were obtained from animal intestinal samples at slaughter (four from pigs and eight from cattle). The remaining 12 isolates were recovered from carcasses at the slaughterhouse (six from pigs and six from cattle). Isolates were first characterised using PCR-ribotype and toxin gene profiles using the multiplex PCR and Genotype CDiff systems (Rodriguez et al., 2012, 2013) (Table 1).

MLVA

All of the C. difficile intestinal and carcass isolates from pigs and cattle were analysed by MLVA. In addition, three isolates from hospital patients (PCR-ribotype 078) and two isolates from nursing home residents (PCR-ribotype UCL 36) were further typed by MLVA in order to compare them with the same PCR-ribotypes found in animals. These human isolates were selected on the basis of their prevalence in Belgian healthcare settings.
DNA extraction was performed using a Chelex 100 Solution 5\% (BioRad) as described previously (O'Neill et al., 1996). A6, B7, C6, E7, G8, CDR5 and CDR60 variablenumber-tandem repeat (VNTR) loci were amplified as previously described with minor modifications (Manzoor et al., 2011). Briefly, three separate PCR duplexes (A6-B7; C6-E7; CDR5-CDR60) and one single PCR (G8) were performed. Forward PCR primers for loci CDR60, E7 and B7 were labelled with hexa-chlorofluorescein (HEX) while the remaining loci (A6, C6, CDR5 and G8) were labelled with 6-carboxyfluorescein (FAM). PCR fragments were analysed using multi-coloured capillary electrophoresis on an ABI3130 automatic sequencer (Applied Biosystems). Electropherograms were analysed using Genemapper V4.0 software (Life Technologies) and copy numbers were determined. The summed absolute difference between two MLVA-typed isolates was the calculated summed tandem repeat difference (STRD) at all seven loci using the Manhattan coefficient (Marsh et al., 2006). Isolates with MLVA STRD $\leq 2$ were indicative of a high degree of genetic relatedness and the value was used to define MLVA clusters (Best et al., 2014). For each VNTR, the Simpson and HunterGaston's diversity indices were calculated using the VNTR diversity and confidence extractor software (V-DICE). ${ }^{1}$

\section{MLST}

C. difficile animal $(n=24)$ and human $(n=13)$ isolates were further characterised by MLST. Isolates were sequence typed using seven housekeeping loci (adk, atpA, $d x r, g l y A, \operatorname{rec} A, \operatorname{sod} A$ and $t p i)$ according to the scheme described by Griffiths et al.

\footnotetext{
1 See: http://www.hpa-bioinformatics.org.uk/cgi-bin/DICI/DICI.pl (accessed 20 February 2014).
} 
(2010). PCR products were purified with a Wizard SV Gel and PCR Clean-Up System Kit (Promega) and sequenced (10 ng of DNA) with PCR forward or reverse primers using the Sanger sequencing reaction BigDye Terminator Kit version 3.1 (Applied Biosystems). Results were analysed using the Geneious program. ${ }^{2}$ The allele number, clade and sequence type (ST) were assigned according to the C. difficile MLST reference database. ${ }^{3}$ A dendrogram was constructed using the Geneious program. Prim's algorithm was applied to draw a minimum-spanning tree from allelic profile data. ${ }^{4}$

Concordance and discriminatory ability of MLVA and MLST methods

Simpson's index of diversity was used to compare the discriminatory ability of MLVA and MLST by measuring the probability that two unrelated strains will be differentiated by the two typing methods (Hunter and Gaston, 1988). Adjusted Wallace coefficient and corresponding confidence intervals (CI) were used to determine the concordance between MLST and MLVA typing methods (Severiano et al., 2011). Simpson's diversity index and concordance calculations were performed with an accessible online tool for quantitative assessment of classification agreement. ${ }^{5}$

\section{Antibiotic resistance Etest testing}

Susceptibility to metronidazole, moxifloxacin and vancomycin was determined by Etest strips (Lucron ELITechGroup) on Brucella Blood Agar with hemin and vitamin K1 (Becton-Dickinson) according to the manufacturer's instructions. Plates were anaerobically incubated at $37{ }^{\circ} \mathrm{C}$ for $48 \mathrm{~h}$. The susceptibility (s) and resistance ( $\mathrm{r}$ ) breakpoints for metronidazole ( $\mathrm{s} \leq 8 \mu \mathrm{g} / \mathrm{mL} ; \mathrm{r} \geq 32 \mu \mathrm{g} / \mathrm{mL}$ ) and moxifloxacin $(\mathrm{s} \leq 2 \mu \mathrm{g} / \mathrm{mL} ; \mathrm{r} \geq 8 \mu \mathrm{g} / \mathrm{mL})$ used for interpretation were those recommended by the Clinical and Laboratory Standard Institute (CLSI, 2010). Vancomycin MIC breakpoints ( $\mathrm{s} \leq 2 \mu \mathrm{g} / \mathrm{mL} ; \mathrm{r} \geq 2 \mu \mathrm{g} / \mathrm{mL}$ ) were established following the European Committee on Antimicrobial Susceptibility Testing (EUCAST) rules. ${ }^{6}$ Bacteroides fragilis ATCL 25285 was included as a quality control.

\section{Antibiotic resistance disc susceptibility testing}

Disc diffusion was performed with standard discs (Becton-Dickinson) of rifampin $(25 \mu \mathrm{g})$, erythromycin $(15 \mu \mathrm{g})$, tetracycline $(30 \mu \mathrm{g})$, chloramphenicol $(30 \mu \mathrm{g})$ and clindamycin $(2 \mu \mathrm{g})$ on Brucella Blood Agar with hemin and vitamin K1 (BectonDickinson) in accordance with the French Society of Microbiology (SFM) guidelines. ${ }^{7}$ The zone diameters were read after $48 \mathrm{~h}$ of anaerobic incubation at $37^{\circ} \mathrm{C}$.

The zone diameters were established as previously reported by Delmée and Avesani (1988): rifampin no zone and $>23 \mathrm{~mm}$; erythromycin $<13 \mathrm{~mm}$ and $>20 \mathrm{~mm}$; tetracycline $<14 \mathrm{~mm}$ and $>23 \mathrm{~mm}$; chloramphenicol $<10 \mathrm{~mm}$ and $>20 \mathrm{~mm}$; clindamycin no zone and $>12 \mathrm{~mm}$. Bacteroides fragilis ATCL 25285 was also tested as a quality control.

\section{Results}

\section{C. difficile MLVA analysis}

A total of 26 C. difficile isolates were typed with MLVA. For PCRribotypes 078 and UCL 36, the animal and carcass isolates were compared with the human isolates circulating in Belgian hospitals and nursing homes. No amplification was obtained in loci A6, CDR5 and B7 for strains belonging to PCR-ribotypes UCL5a, UCL11 and 078 isolated from pig and cattle intestinal contents and carcasses. In contrast, the three human PCR-ribotypes 078 were positive for both loci A6 and B7 with invariable results in locus A6 and two amplifications in locus B7. For the PCR-ribotype UCL 036, although the two human isolates were different from the pig carcass strains they were similar to each other with a STRD $<2$. All animal isolates belonging to the same PCR-ribotype (078, 014, UCL 16U or UCL 36) obtained from the same animal species (pig or cow) and from the same type of sample (intestinal contents or carcasses) were clonal by MLVA (STRD $\leq 2$ ). Furthermore, clonal animal isolates were detected not only within the same sampling day but also among strains collected in different dates (Table 2).

\footnotetext{
2 See: http://www.geneious.com/ (accessed 7 November 2014).

3 See: http://pubmlst.org/cdifficile/ (accessed 20 November 2014).

4 See:

http://www.webcitation.org/getfile?fileid=40a0115241957fa1 cf077cae26bb54650 772ce9c (accessed 20 February 2014).

5 See: http://www.comparingpartitions.info (accessed 23 February 2015).

6 See: http://www.eucast.org (accessed 13 September 2014).

7 See: http://www.sfm-microbiologie.org (accessed 13 September 2014).
}

The large number of MLVA clusters identified in this study is probably related with the allelic diversity observed among the MLVA loci. The highest number of different repeats in the sample set was found for loci C6 $(n=24)$ and B6 $(n=15)$. In contrast, loci CDR5 and CDR60 presented the lowest allelic diversity. However, these loci were valuable to discriminate isolates PCR-ribotype 023, UCL 16u and 081 (CDR5), and isolates PCR-ribotype 015, 081, 023, UCL 118 and UCL 254 (CDR60) (Table 3).

\section{C. difficile MLST analysis}

A total of 12 different STs were found by MLST. ST assignment was not possible for two isolates (PCR-ribotypes UCL 254 and 014) as no loci sequence combination matched the allelic profile of the isolates. A clear concordance was found between most of the PCRribotypes studied and ST. However, PCR-ribotype 014 correlated with two different STs (49 and 2) while ST 11 and ST 49 were assigned to more than one different PCR-ribotype (Fig. 1). Most of the isolates belonged to clade 1 , which cluster a great variety of PCRribotypes, including the six non-toxigenic types. Clade 5 was attributed to PCR-ribotypes 078, UCL 5a and UCL 11 whereas only one isolate (PCR-ribotype 023 ) was related to clade 3.

A phylogenetic tree shows a correlation between isolates with the same PCR-ribotype regardless of their origin (carcass, intestinal contents or human faeces) (Fig. 1). According to the minimum spanning tree, the nearest neighbour strains belonged to ST 49, ST 2 , ST 14, ST 45 and ST 6, which corresponded with PCR-ribotypes 014, 015, UCL 16U, UCL 16L, UCL 118 and UCL 46 respectively (Fig. 2).

\section{Discriminatory power and concordance among genotyping methods}

Results of Simpson's diversity index showed that MLVA had the greatest discriminatory power, with and index of diversity value of 0.979 (Table 4). MLVA identified a total of 21 different types, of which six grouped more than one isolate. However, most of these types $(n=15)$ were defined by a single isolate. MLST only distinguished 12 different STs (sequence types) generating an index of diversity value of 0.868 . Wallace coefficient of concordance among genotyping methods reveals that the probability of predicting the correct ST based on knowledge of MLVA type was $71 \%$. There were four STs that represented multiple MLVA types (comprising between two and five different MLVA types for one ST). For example, MLST could not discriminate between L, M and N MLVA groups, classified as ST15 (Fig. 1).

\section{C. difficile antimicrobial susceptibility}

All human and animal isolates were susceptible to vancomycin, metronidazole, chloramphenicol and rifampicin. In addition, all of the isolates showed full sensibility to tetracycline except for PCRribotypes UCL 5a and UCL 11 which both showed intermediate resistance to this drug. Only two isolates (one animal and one human strain) belonging to PCR-ribotype 078 and the two isolates belonging to PCR-ribotype UCL 5a showed in vitro resistance to moxifloxacin by Etest. These results were correlated with the presence of a mutation in the gyrA gene by Genotype CDiff system. Moreover, four isolates assigned to PCR-ribotypes UCL $36(n=1)$, UCL $11(n=2)$ and UCL $078(n=1)$ were resistant to clindamycin, while resistance to erythromycin was detected in $13 / 37$ (35.1\%) isolates belonging to PCR-ribotypes UCL 36, UCL 103, 078 and UCL 5a (Fig. 1).

\section{Discussion}

In studies of $C$. difficile isolates, MLVA and MLST have shown limited application to date (Griffiths et al., 2010) and few studies have investigated the phylogenic relatedness of isolates from humans 
Table 2

Characterisation of the 26 main C. difficile types by MLVA.

\begin{tabular}{|c|c|c|c|c|c|c|c|c|c|c|c|c|}
\hline \multirow[t]{2}{*}{ PCR-ribotype } & \multicolumn{8}{|c|}{ MLVA profile } & \multirow{2}{*}{$\begin{array}{c}\text { Strain } \\
\text { identification }\end{array}$} & \multirow{2}{*}{$\begin{array}{l}\text { MLVA } \\
\text { type }\end{array}$} & \multirow{2}{*}{$\begin{array}{l}\text { Sample } \\
\text { type }\end{array}$} & \multirow{2}{*}{$\begin{array}{l}\text { Date of } \\
\text { the isolation }\end{array}$} \\
\hline & A6 & B7 & C6 & E7 & G8 & CDR5 & CDR60 & Total & & & & \\
\hline \multirow[t]{10}{*}{078} & 10.6 & 9.1 & 37 & 8.1 & 9.8 & NA & 2.2 & $76.8^{c}$ & 5828 & A & Human & 2011 \\
\hline & & $25.1^{\mathrm{a}}$ & $38^{\mathrm{a}}$ & & & & $\begin{array}{l}8.7 \\
4.2^{\mathrm{b}}\end{array}$ & & & & & \\
\hline & 10.6 & 9.1 & 37 & 8.1 & 10.7 & NA & 2.2 & $77.7^{c}$ & 5063 & A & Human & 2010 \\
\hline & & $38.3^{a}$ & & $14.3^{\mathrm{a}}$ & & & $\begin{array}{l}8.7 \\
4.3^{b}\end{array}$ & & & & & \\
\hline & 10.6 & $9.2^{\mathrm{a}}$ & 26.5 & 9.1 & 12.7 & NA & 2.2 & $70.2^{c}$ & 4667 & B & Human & 2010 \\
\hline & & 12 & & $10.9^{a}$ & & & & & & & & \\
\hline & NA & NA & 30.5 & 8.2 & 11.7 & NA & $\begin{array}{l}2.2 \\
1.6^{\mathrm{a}}\end{array}$ & $52.6^{c}$ & 6136 & $\mathrm{C}$ & Pig IC & $22 / 06 / 2011$ \\
\hline & NA & NA & 30.5 & 8.1 & 11.7 & NA & $\begin{array}{l}2.2 \\
1.6^{\mathrm{a}}\end{array}$ & $52.5^{c}$ & 6135 & C & Pig IC & $22 / 06 / 2011$ \\
\hline & NA & NA & 33.7 & 8 & 10.8 & NA & $\begin{array}{l}2.2 \\
1.6^{\mathrm{a}}\end{array}$ & $57.8^{c}$ & 7485 & $\mathrm{D}$ & Cow IC & $22 / 11 / 2011$ \\
\hline & NA & NA & 34.8 & 8 & 11.7 & NA & $\begin{array}{l}2.2 \\
1.6^{\mathrm{a}}\end{array}$ & $56.7^{c}$ & 6423 & $\mathrm{D}$ & Cow IC & $04 / 11 / 2011$ \\
\hline UCL 11 & NA & NA & 41.9 & 8 & 10.8 & NA & 2.2 & 63.8 & 6412 & $E$ & Beef C & $22 / 11 / 2011$ \\
\hline UCL 5a & NA & NA & 28.5 & 8 & 11.7 & NA & $\begin{array}{l}2.2 \\
1.6^{\mathrm{a}}\end{array}$ & $50.4^{c}$ & 6408 & $\mathrm{~F}$ & Beef C & $07 / 10 / 2011$ \\
\hline \multirow[t]{4}{*}{014} & 27.9 & 22.2 & $\begin{array}{l}25.5 \\
24.4^{\mathrm{a}}\end{array}$ & 6 & 7 & 6.8 & 7.2 & $102.6^{c}$ & 6420 & G & Cow IC & $18 / 11 / 2011$ \\
\hline & 19.2 & 13.1 & 27.5 & 7 & 9.9 & 6.8 & 7.2 & 90.7 & 7071 & $\mathrm{H}$ & Pork C & $29 / 11 / 2011$ \\
\hline & 20.2 & 13.1 & $\begin{array}{l}27.5 \\
26.5^{a}\end{array}$ & 7 & 9.9 & 6.8 & 7.2 & $91.7^{c}$ & 6414 & $\mathrm{H}$ & Pork C & $29 / 11 / 2011$ \\
\hline & 19.3 & 13.1 & $\begin{array}{l}27.5 \\
26.5^{\mathrm{a}}\end{array}$ & 7 & 9.9 & 6.8 & 7.2 & $91.8^{c}$ & 6415 & $\mathrm{H}$ & Pork C & $29 / 11 / 2011$ \\
\hline UCL 16L & 25 & 12.1 & 40.9 & 3.9 & 8.9 & 6.8 & 10.2 & 107.8 & 6427 & I & Cow IC & $23 / 09 / 2011$ \\
\hline \multirow[t]{2}{*}{ UCL 16U } & 34.9 & 9 & 24.4 & 6 & 8.9 & 7.8 & 7.2 & 98.2 & 6410 & $\mathrm{~J}$ & Beef C & $18 / 11 / 2011$ \\
\hline & 35.9 & 9 & 25.4 & 6 & 8.9 & 7.8 & 7.2 & 100.2 & 6413 & $\mathrm{~J}$ & Beef C & $18 / 11 / 2011$ \\
\hline 015 & 14.5 & 14 & 48.7 & 2.8 & 10.8 & 4.2 & 6.2 & 101.2 & 6409 & $\mathrm{~K}$ & Beef C & $07 / 10 / 2011$ \\
\hline \multirow[t]{4}{*}{ UCL36 } & 31.8 & 18.1 & 35.8 & 8 & 10.8 & 4.9 & 11.2 & 118.5 & 8387 & $\mathrm{~L}$ & Human & $19 / 04 / 2013$ \\
\hline & 19.2 & 17 & 42.8 & 8 & 9.9 & 4.9 & 10.2 & 112 & 8378 & M & Human & $08 / 03 / 2013$ \\
\hline & 17.3 & 15.1 & 20.4 & 8 & 10.8 & 4.9 & 12.2 & 88.7 & 7083 & $\mathrm{~N}$ & Pork C & $29 / 11 / 2011$ \\
\hline & 17.3 & 18.1 & 19.4 & 8 & 10.8 & 4.8 & 12.2 & 90.6 & 7078 & $\mathrm{~N}$ & Pork C & $29 / 11 / 2011$ \\
\hline \multirow[t]{3}{*}{081} & 27.9 & 21 & 51.8 & 2.9 & 7 & 4.9 & 27.3 & 142.8 & 7077 & $\mathrm{O}$ & Pork C & $29 / 11 / 2011$ \\
\hline & & & & $26^{\mathrm{a}}$ & & & & & & & & \\
\hline & 26 & 14.9 & 40 & 2.7 & 8.9 & 5.9 & 26.2 & 124.6 & 6140 & $\mathrm{P}$ & Pig IC & $23 / 09 / 2011$ \\
\hline UCL 118 & 27.9 & 19 & 18.4 & 7 & 8.9 & 4.2 & 8.2 & 93.6 & 6421 & Q & Cow IC & $23 / 09 / 2011$ \\
\hline UCL 270 & 37.9 & 14.1 & 15.4 & 6 & 13.7 & 4.8 & 11.2 & 103.1 & 6425 & $\mathrm{R}$ & Cow IC & $23 / 09 / 2011$ \\
\hline UCL 103 & 34.9 & 12.1 & 38 & 8 & 11.8 & 4.8 & 12.2 & 121.8 & 7487 & $S$ & Cow IC & $30 / 09 / 2011$ \\
\hline UCL 254 & 25 & 13.1 & 29.5 & 5 & 11.8 & 4.2 & 3.3 & 91.9 & 6430 & $\mathrm{~T}$ & Cow IC & $22 / 11 / 2011$ \\
\hline 023 & NA & 18.1 & 34.7 & 8.1 & 14.6 & 8.8 & 2.3 & 86.6 & 6411 & $U$ & Pork C & $22 / 11 / 2011$ \\
\hline
\end{tabular}

NA, no amplification; $C$, carcass; IC, intestinal contents.

a Two fragments amplified for the same locus.

b Three fragments amplified for the same locus.

c When there were two or more amplifications for the same fragment, only the first value indicated in the table has been taken into account to make the sum (total).

and from different animal species isolated in a restricted geographical region. Lemée et al. (2005) used a set of 74 C. difficile isolates from various hosts, geographic sources and PCR-ribotypes to investigate the allelic diversity and population structure of the isolates by MLST. Bakker et al. (2010) studied the relatedness of human and porcine C. difficile PCR-ribotype 078 isolates from four European countries using MLVA. In the present study, characterisation of C. difficile isolates was achieved using both MLST and MLVA methods. Six clonal groups of strains were obtained from the same animal species, irrespective of the isolation date. Furthermore, MLST revealed that all of the other human and animal isolates with a given PCR-ribotype clustered in the same lineage.

Table 3

Simpson and Hunter-Gaston diversity indices of MLVA VNTRs studied.

\begin{tabular}{|c|c|c|c|c|c|c|c|c|c|}
\hline \multicolumn{5}{|c|}{ Simpson diversity index } & \multicolumn{5}{|c|}{ Hunter-Gaston diversity index } \\
\hline Locus & Diversity index & Confidence interval & $\mathrm{K}$ & $\operatorname{Max}(\mathrm{pi})$ & Locus & Diversity index & Confidence interval & K & $\operatorname{Max}(p i)$ \\
\hline C6 & 0.952 & $0.934-0.969$ & 24 & 0.107 & C6 & 0.987 & 0.969-1.000 & 24 & 0.107 \\
\hline B7 & 0.895 & $0.845-0.945$ & 15 & 0.214 & B7 & 0.929 & $0.879-0.979$ & 15 & 0.214 \\
\hline A6 & 0.885 & $0.825-0.946$ & 14 & 0.250 & A6 & 0.918 & $0.857-0.979$ & 14 & 0.250 \\
\hline G8 & 0.865 & $0.818-0.912$ & 11 & 0.214 & G8 & 0.897 & $0.850-0.944$ & 11 & 0.214 \\
\hline E7 & 0.827 & $0.745-0.908$ & 11 & 0.321 & E7 & 0.857 & $0.775-0.939$ & 11 & 0.321 \\
\hline CDR60 & 0.821 & $0.736-0.907$ & 11 & 0.321 & CDR60 & 0.852 & $0.766-0.938$ & 11 & 0.321 \\
\hline CDR5 & 0.814 & $0.739-0.888$ & 8 & 0.321 & CDR5 & 0.844 & $0.770-0.918$ & 8 & 0.321 \\
\hline
\end{tabular}

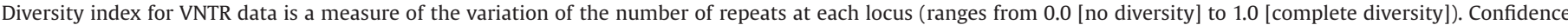

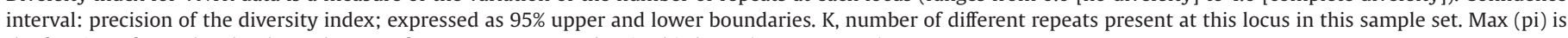
the fraction of samples that have the most frequent repeat number in this locus (range 0.0-1.0). 


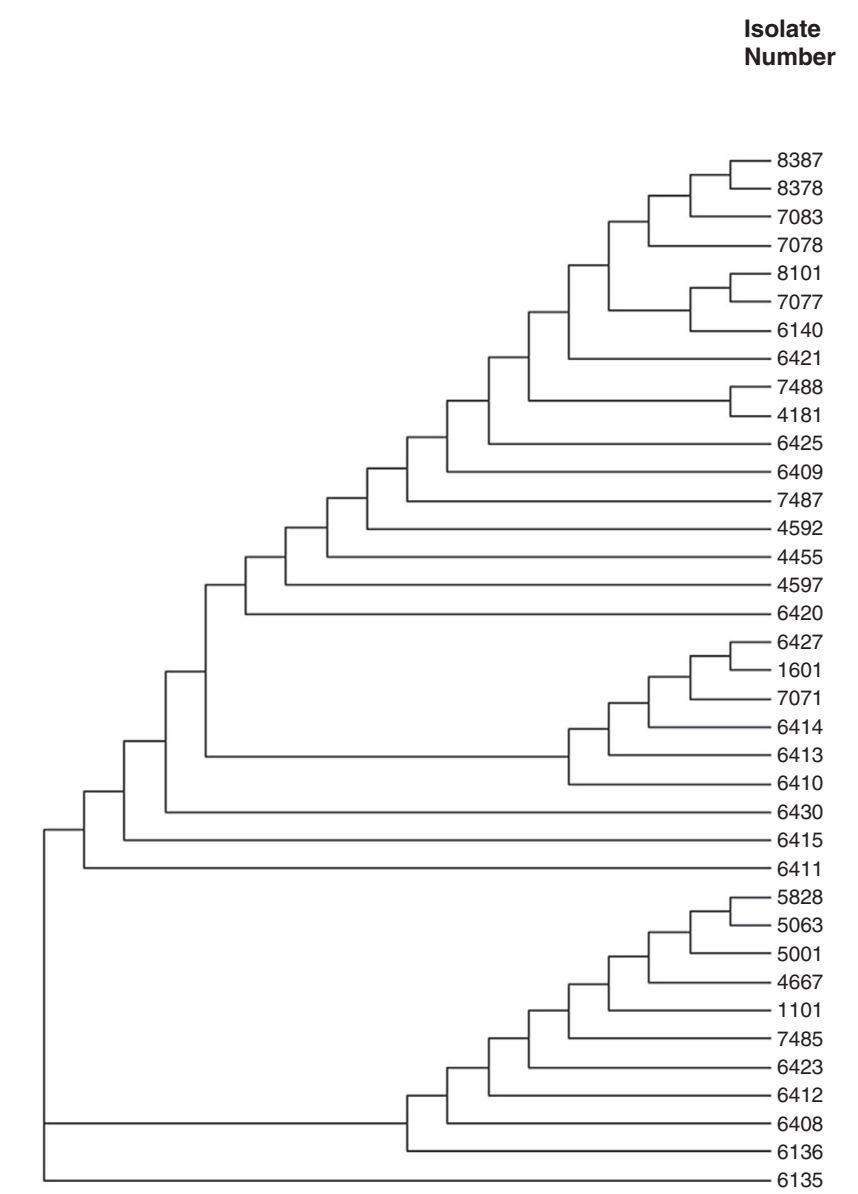

ST

rece

Clade (atp, adk, dxr, glyA recA, $\operatorname{sod} A$, tpi)

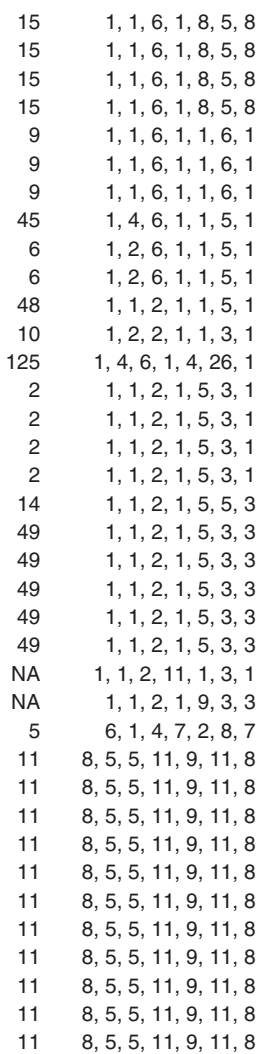

1
1
1
1
1
1
1
1
1
1
1
1
1
1
1
1
1
1
1
1
1
1
1
NA
NA
3
5
5
5
5
5
5
5
5
5
5
5

1
1
1
1
1
1
1
1
1
1
1
1
1
1
1
1
1
1
1
1
1
1

UCL 36
UCL 36
UCL 36
UCL 36
081
081
081
UCL 118
UCL 46
UCL 46
UCL 270
015
UCL 103
014
014
015
014
UCL $16 L$
UCL $16 \mathrm{U}$
014
014
UCL $16 \mathrm{U}$
UCL $16 \mathrm{U}$
UCL 254
014
023
078
078
UCL $5 a$
078
UCL 11
078
078
UCL 11
078
078

PCR CC-R TE-R E-R MXF-R

Origin

Fig. 1. Neighbour-joining phylogenetic tree constructed with the MLST results showing the relationships between animal and human C. difficile strains. Allelic Profile: atp, adk, dxr, glyA, recA, sodA, tpi; ST, sequence type; NA, no available data; MXF-R, moxifloxacin resistance; E-R, erythromycin resistance; CC-R, clindamycin resistance; TE-R, tetracycline resistance; I, intermediate antimicrobial resistance.

Three of the six clonal groups of strains were identified as PCRribotype 078. They were detected in two hospitalised patients, in two cattle intestinal contents at slaughter and in two pigs' intestinal contents also obtained at the slaughterhouse (specifically, in the viscera processing area). The human PCR-ribotype 078 clonal strains were isolated from two different Belgian provinces in two different years (unpublished data). The porcine strains were obtained on the same sampling day in one slaughterhouse; this could suggest a widespread dissemination of $C$. difficile at the slaughterhouse (Rodriguez et al., 2012) or even in the pig farm, as previously described (Keessen et al., 2011). The same conditions were observed for the two PCR-ribotype 078 isolates from cattle intestinal contents. These were considered clonal by MLVA, but in this case the isolates were obtained on two different sampling days and the animals proceeded from different herds. As previously suggested, this finding may indicate either an epidemiological connection between farms (Scheeberg et al., 2013) or slaughterhouse contamination. However, clonal strains were not detected among $C$. difficile isolates from pig and cattle origins, which indicates that crosscontamination between the two slaughter lines (bovine and porcine) during processing is unlikely.

Identical $C$. difficile strains were also detected in the same animal species for PCR-ribotypes 014, UCL 16U and UCL 36. These results indicate that clonal $C$. difficile strains are circulating among the same animal species (including humans), although interspecies transmission was not evident. In a previous study, Kenetsch et al. (2014) reported transmission between farmers and pigs but the authors did not exclude the possibility of a common environmental source of $C$. difficile for both populations. In addition, more than half of the sequenced farmer/pig pairs were not clonal. As in our study, isolates were obtained from subjects localised in different geographical regions and in different environments. It was consequently very unlikely that identical $C$. difficile isolates would be found among the different hosts although MLST and MLVA revealed a close relation between them. Furthermore, for PCR-ribotype 078 MLVA showed a higher genetic association between pig and cattle $C$. difficile isolates $($ STRD $\leq 6)$ than between animal and human isolates (STRD $\geq 20$ ).

Varshney et al. (2014) observed significant genotypic and phenotypic differences between meat and human isolates for a variety of PCR-ribotypes, while a few meat isolates (including PCR-ribotype 078) were very similar to human $C$. difficile strains. It has been suggested that relatedness between human and animal isolates of PCRribotype 078 is a consequence of less natural variability in this type than in other types (Bakker et al., 2010). However, our results indicate genetic differences that clearly distinguish between human and animal isolates.

As has been previously reported, MLST shows less discriminatory power than MLVA but does establish the $C$. difficile genetic lineage (Marsh et al., 2010). In our study some limitations of the MLVA technique were observed. Three loci, including A6, B7 and CDR5, did not seem to be stable and disappeared from some isolates, recording a null result. Variations in loci total size were also observed for some of the isolates, possibly due to the weak stability of the loci in vitro after several passages which may cause isolates with closely related MLVA profiles to appear non-clonal (Wuyts et al., 


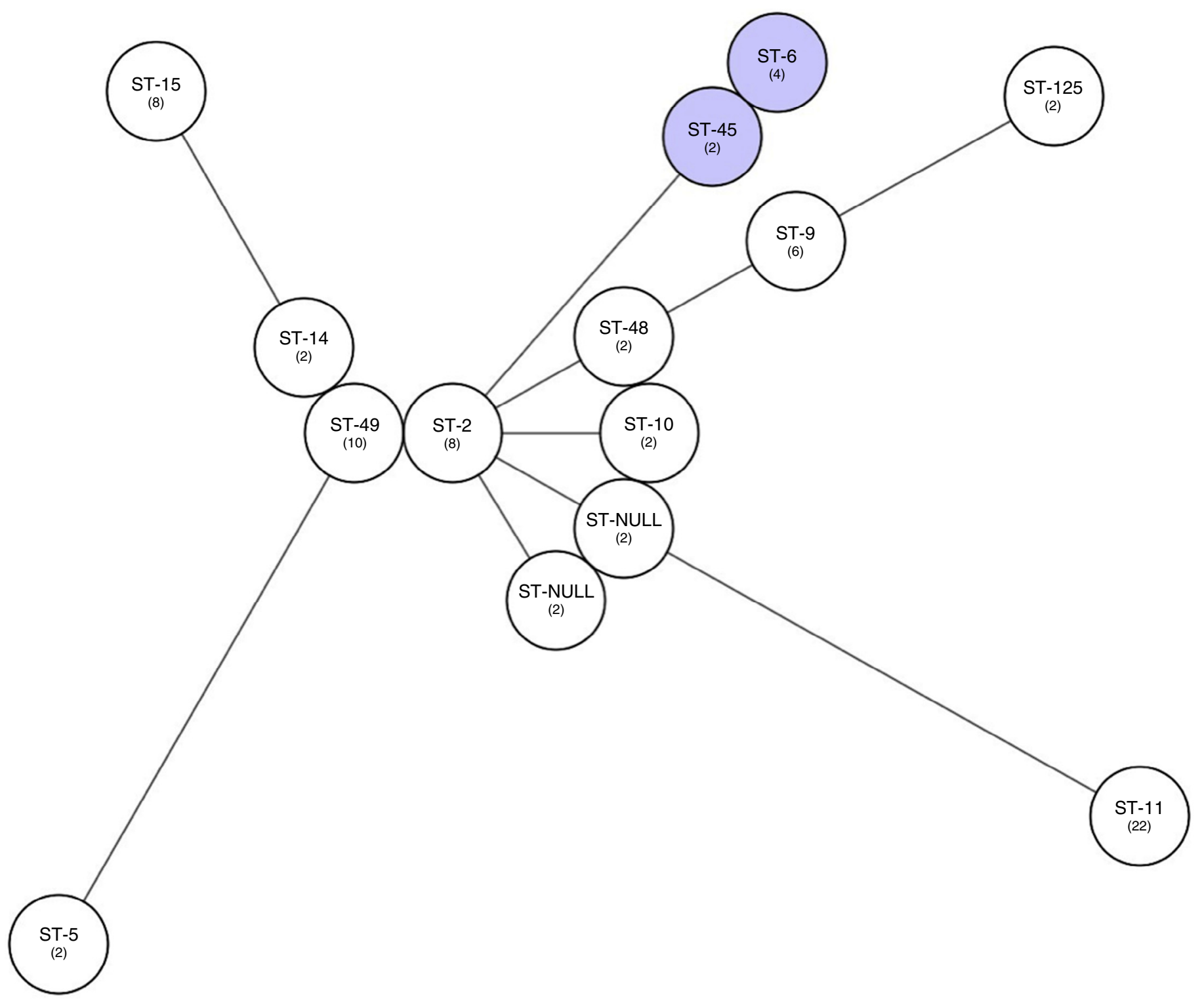

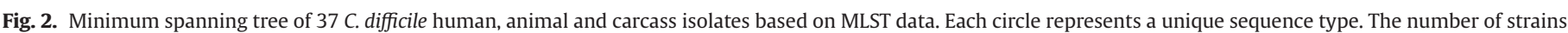

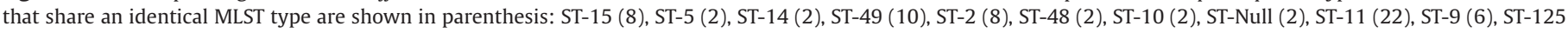
(2), ST-45 (2), ST-6 (4).

2013). Further studies to investigate the stability of these loci are therefore required. In addition, MLVA provides little insight regarding genetic relatedness. In consequence, it may be useful to combine both methods (MLVA and MLST) in order to resolve phylogenetic diversity (Zaiss et al., 2009) although the best alternative could be whole genome sequencing, which is generally considered to be the next generation tool to type bacterial strains.

Resistance of $C$. difficile to multiple antimicrobials has been described in several previous studies in both humans and animals (Pelaez et al., 2013; Pirs et al., 2013). Even though some isolates were resistant to both moxifloxacin and erythromycin or to clindamycin and erythromycin, no association between antimicrobial resistance and toxigenic isolates was observed in our study, echoing the results of previous work by Pituch et al. (2005). Furthermore, for a given PCR-ribotype, human and animal strains presented a similar susceptibility to the antimicrobials we tested.

Our study has some limitations. Firstly, only two different human PCR-ribotypes were analysed by MLVA because the other types found in animals were either not available in the human collections in our laboratory or have not been frequently isolated in previous studies

Table 4

Simpson's index of diversity and adjusted Wallace coefficient of concordance among genotyping methods.

\begin{tabular}{|c|c|c|c|c|c|}
\hline \multirow[t]{2}{*}{ Method } & \multicolumn{3}{|c|}{ Simpson's diversity index } & \multicolumn{2}{|c|}{ Adjusted Wallace coefficient of concordance (95\% CI) } \\
\hline & Number of units & ID & $95 \% \mathrm{CI}$ & Sequence typing MLST & MLVA type \\
\hline MLVA & 21 & 0.979 & $0.961-0.997$ & $0.712(0.440-0.984)$ & \\
\hline MLST & 12 & 0.868 & $0.780-0.955$ & & $0.101(0.000-0.234)$ \\
\hline
\end{tabular}

ID, index of diversity; $\mathrm{CI}$, confidence interval. 
conducted in Belgian hospitals or nursing homes. Additionally, the lack of sufficient reference strains in our laboratory only allowed us to identify five ribotype profiles corresponding to an international collection number while the remaining PCR-ribotypes were identified using an internal nomenclature.

\section{Conclusions}

This study shows that clonal $C$. difficile strains circulate among the same animal species or among human patients, irrespective of the geographic area and the isolation date. The typing methods used also reveal close relationships between isolates of different species, but less genetic similarity among human and animal strains. However, animal and human strains cluster in the same lineage. Our data evidence the need for highly discriminatory genotyping methods, not only to elucidate the possible transmission routes between humans and animals but also to investigate animal-toanimal transmission in herds or cross-contamination at slaughterhouses.

\section{Conflict of interest statement}

None of the authors of this paper has a financial or personal relationship with other people or organisations that could inappropriately influence or bias the content of the paper.

\section{Acknowledgements}

This study was funded by the Federal Public Service of Health, Food Chain Safety and Environment (contract RF09/6226). The authors would like to thank the public slaughterhouse of LiègeWaremme for permission to sample. Our most sincere thanks go to Cate Chapman and Josh Jones for their support in editing the manuscript. Preliminary results were presented as an abstract at the IAFP European Symposium of Food Safety, Budapest, 7-9 May 2014 and obtained the award in the poster competition.

\section{References}

Bakker, D., Corver, J., Harmanus, C., Goorhuis, A., Keessen, E.C., Fawley, W.N., Wilcox, M.H., Kuijper, E.J., 2010. Relatedness of human and animal Clostridium difficile PCR ribotype 078 isolates determined on the basis of multilocus variable-number tandem-repeat analysis and tetracycline resistance. Journal of Clinical Microbiology 48, 3744-3749.

Best, E.L., Parnell, P., Thirkell, G., Verity, P., Copland, M., Elsa, P., Denton, M., Hobson, R.P., Wilcox, M.H., 2014. Effectiveness of deep cleaning followed by hydrogen peroxide decontamination during high Clostridium difficile infection incidence. Journal of Hospital Infection 87, 25-33.

CLSI, 2010. Clinical and Laboratory Standard Institute. http://clsi.org/ (accessed 20 January 2015).

Debast, S.B., van Leengoed, L.A., Goorhuis, A., Harmanus, C., Kuijper, E.J., Bergwerff, A.A., 2009. Clostridium difficile PCR ribotype 078 toxinotype $V$ found in diarrhoeal pigs identical to isolates from affected humans. Environmental Microbiology 11, 505-511.

Delmée, M., Avesani, V., 1988. Correlation between serogroup and susceptibility to chloramphenicol, clindamycin, erythromycin, rifampicin and tetracycline among 308 isolates of Clostridium difficile. Journal of Antimicrobial Chemotherapy 22, 325-331.

Griffiths, D., Fawley, W., Kachrimanidou, M., Bowden, R., Crook, D.W., Fung, R., Golubchik, T., Harding, R.M., Jeffery, M., Jolley, K.A., et al., 2010. Multilocus sequence typing of Clostridium difficile. Journal of Clinical Microbiology 48, $770-778$.

Hargreaves, K.R., Coluin, H.V., Patel, K.V., Clokie, J.J., Clokie, M.R., 2013. Genetically diverse Clostridium difficile strains harbouring abundant prophages in an estuarine environment. Applied Environmental Microbiology 79, 6236-6243.

Hensgens, M.P.M., Keessen, E.C., Squire, M.M., Riley, T.V., Koene, M.G.J., de Boer, E., Lipman, L.J.A., Kuijper, E.J., 2012. Clostridium difficile infection in the community: A zoonotic disease? Clinical Microbiology Infection 18, 635-645.

Hunter, P.R., Gaston, M.A., 1988. Numerical index of the discriminatory ability of typing systems: An application of Simpson's index of diversity. Journal of Clinical Microbiology 26, 2465-2466.

Jones, A.M., Kuijper, E.J., Wilcox, M.H., 2013. Clostridium difficile: A European perspective. Journal of Infection 66, 115-128.
Keessen, E.C., Donswijk, C.J., Hol, S.P., Hermanus, C., Kuijper, E.J., Lipman, L.J., 2011 Arial dissemination of Clostridium difficile on a pig farm and its environment. Environmental Research 111, 1027-1032.

Kenetsch, C.W., Connor, T.R., Mutreja, A., van Dorp, S.M., Sanders, I.M., Browne, H.P., Harris, D., Lipman, L., Keessen, E.C., Corver, J., 2014. Whole genome sequencing reveals potential spread of Clostridium difficile between humans and farm animals in the Netherlands, 2002 to 2011. Eurosurveillance 19, 20954.

Killgore, G., Thompson, A., Johnson, S., Brazier, J., Kuijper, E., Pepin, J., Frost, E.H., Svelkoul, P., Nicholson, B., van den Berg, R.J., et al., 2008. Comparison of seven techniques for typing international epidemic strains of Clostridium difficile: Restriction endonuclease analysis, pulsed-field gel electrophoresis, PCR-ribotyping, multilocus sequence typing, multilocus variable-number tandem-repeat analysis, amplified fragment length polymorphism, and surface layer protein A gene sequence typing. Journal of Clinical Microbiology 46, 431-437.

Lemée, L., Dhalluin, A., Pestel-Caron, M., Lemeland, J.F., Pons, J.L., 2004. Multilocus sequence typing of humans and animal Clostridium difficile isolates of various toxigenic types. Journal of Clinical Microbiology 42, 2609-2617.

Lemée, L., Bourgeois, I., Ruffin, E., Collignon, A., Lemeland, J.F., Pons, J.L., 2005 Multilocus sequence analysis and comparative evolution of virulence-associated genes and housekeeping genes of Clostridium difficile. Microbiology (Reading, England) 151, 3171-3180.

Manzoor, S.E., Tanner, H.E., Marriott, C.L., Brazier, K.S., Hardy, K.J., Platt, S., Hawkey P.M., 2011. Extended multilocus variable-tandem-repeat analysis of Clostridium difficile correlates exactly with ribotype and enables identification of hospital transmission. Journal of Clinical Microbiology 49, 3523-3530.

Marsh, J.W., O’Leary, M.M., Shutt, K.A., Pasculle, A.W., Johnson, S., Gerding, D.N., Muto, C.A., Harrison, L.H., 2006. Multilocus variable-number tandem-repeat analysis for investigation of $C$. difficile transmission in hospitals. Journal of Clinical Microbiology 44, 2558-2566.

Marsh, J.W., O'Leary, M.M., Shutt, K.A., Sambol, S.P., Johnson, S., Gerding, D.N., Harrison, L.H., 2010. Multilocus variable-number tandem-repeat analysis and multilocus sequence typing reveal genetic relationships among Clostridium difficile isolates genotyped by restriction endonuclease analysis. Journal of Clinical Microbiology $48,412-418$.

O'Neill, G.L., Ogunsola, F.T., Brazier, J.S., Duerden, B.I., 1996. Modification of a PCR ribotyping method for application as a routine typing scheme for Clostridium difficile. Anaerobe 2, 205-209.

Pelaez, T., Alcala, L., Blanco, J.L., Alvarez-Perez, S., Marin, M., Martin-Lopez, A., Catalan, P., Reigadas, E., Garcia, M.E., Bouza, E., 2013. Characterization of swine isolates of Clostridium difficile in Spain: A potential source of epidemic multidrug resistant strains? Anaerobe 22, 45-49.

Pirs, T., Avbersek, J., Zdovc, I., Krt, B., Andlovic, A., Lejko-Zupanc, T., Rupnik, M., Ocepek, M., 2013. Antimicrobial susceptibility of animal and human isolates of Clostridium difficile by broth microdilution. Journal of Medical Microbiology 62, 14781485.

Pituch, H., Obuch-Woszczatyriski, P., Wultanska, D., Meisel-Mikolajczyk, F., Luczak, M., 2005. A survey of metronidazole and vancomycin resistance in strains of Clostridium difficile isolated in Warsaw, Poland. Anaerobe 11, 197-199.

Rodriguez, C., Taminiau, B., Van Broeck, J., Avesani, V., Delmée, M., Daube, G., 2012. Clostridium difficile in young farm animals and slaughter animals in Belgium. Anaerobe 18, 621-625.

Rodriguez, C., Avesani, V., Van Broeck, J., Taminiau, B., Delmée, M., Daube, G., 2013. Presence of Clostridium difficile in pigs and cattle intestinal contents and carcass contamination at the slaughterhouse in Belgium. International Journal of Food Microbiology 2, 256-262.

Rodriguez-Palacios, A., Borgmann, S., Kline, T.R., LeJeune, J.T., 2013. Clostridium difficile in foods and animals: History and measures to reduce exposure. Animal Health Research Review 14, 11-29.

Scheeberg, A., Neubauer, H., Schmoock, G., Baier, S., Harlizius, J., Nienhoff, H., Brase, K., Zimmermann, S., Seyboldt, C., 2013. Clostridium difficile genotypes in piglet populations in Germany. Journal of Clinical Microbiology 51, 3796.

Severiano, A., Pinto, F.R., Ramirez, M., Carriço, J.A., 2011. Adjusted Wallace coefficient as a measure of congruence between typing methods. Journal of Clinical Microbiology 49, 3997-4000.

Stabler, R.A., Dawson, L.F., Valiente, E., Cairns, M.D., Martin, M.J., Donahue, E.H., Riley, T.V., Songer, J.G., Kuijper, E.J., Dingle, K.E., et al., 2012. Macro and micro diversity of Clostridium difficile isolates from diverse sources and geographical locations. PLoS ONE 7, e31559.

Susick, E.K., Putnam, M., Bermudez, D.M., Thakur, S., 2012. Longitudinal study comparing the dynamics of Clostridium difficile in conventional and antimicrobial free pigs at farm and slaughter. Veterinary Microbiology 25, 172-178.

Varshney, J.B., Very, K.J., Williams, J.L., Hegarty, J.P., Stewart, D.B., Lumadue, J., Venkitanarayanan, K., Jayarao, B.M., 2014. Characterization of Clostridium difficile isolates from human faecal samples and retail meat from Pennsylvania. Foodborne Pathogens Diseases 11, 822-829.

Wuyts, V., Mattheus, W., De Lamine de Bex, G., Wildemauwe, C., Roosens, N.H.C., Marchal, K., De Keersmaecker, S.C.J., Bertrand, S., 2013. MLVA as a tool for public health surveillance of human Salmonella typhimurium: Prospective study in Belgium and evaluation of MLVA loci stability. PLoS ONE 8, e84055.

Zaiss, N.H., Rupnik, M., Kuijper, E.J., Harmanus, C., Michielsen, D., Janssens, K., Nübel, H., 2009. Typing Clostridium difficile strains based on tandem repeat sequences. BMC Microbiology 8, 6.

Zidaric, V., Beigot, S., Lapajne, S., Rupnik, M., 2010. The occurrence and high diversity of Clostridium difficile genotypes in rivers. Anaerobe 16, 371-375. 